\title{
Diagnosing non-cavitated lesions in epidemiological studies: practical and scientific considerations*
}

Joana Christina Carvalho(a) Heliana Dantas Mestrinho(b)

(a) School of Medicine and Dentistry, Catholic University of Louvain, Belgium.

(b) Department of Odontology, Faculty of Health Sciences, Universidade de Brasília UnB, Brasília, DF, Brazil.

* Paper presented at the "Equity, Social Inclusion and Oral Health Promotion: Major Challenges" International Symposium, Held at the $18^{\text {th }}$ Congress of the Brazilian Association for Oral Health Promotion (Associação Brasileira de Odontologia de Promoção de Saúde - ABOPREV), April 2013, Bauru, SP, Brazil.

Declaration of Interests: The authors certify that they have no commercial or associative interest that represents a conflict of interest in connection with the manuscript.

Corresponding Author: Joana Christina Carvalho

E-mail: joana.carvalho@uclouvain.be

htrp://dx.doi.org/10.1590/S1806-83242013005000036 Epub Jan 14, 2014

Submitted: Jul 22, 2013

Accepted for publication: Sep 01, 2013

Last revision: Oct 18, 2013
Abstract: Over the last decade, there has been growing interest in diagnosing non-cavitated lesions in epidemiological studies involving large numbers of preschool children, schoolchildren and young adults. In this context, assessment of lesions characteristics indicating whether or not there is ongoing mineral loss is also considered relevant. The reasoning sustained by these studies is that diagnosis of the caries process limited to the cavitated level is no longer in accordance with current state-of-the-art knowledge in cariology. This paper highlights one topic of the lecture entitled "Caries Process: Evolving Evidence and Understanding," presented at the $18^{\text {th }}$ Congress of the Brazilian Association for Oral Health Promotion (Associação Brasileira de Odontologia de Promoção de Saúde - ABOPREV) in April 2013. In the framework of epidemiological studies, the interest in diagnosing active and inactive non-cavitated lesions was elucidated. However, relevant questions associated with the diagnosis of non-cavitated lesions that might raise concerns among researchers and health administrators were not addressed. The present paper aims to bring these questions into discussion. The contribution of this discussion in terms of developing the understanding of caries decline is analyzed by using data from a caries trends study of Brazilian preschool children residing in the Federal District of Brazil as an example. The inclusion of active and inactive non-cavitated lesions in the diagnosis of the caries process allowed us to demonstrate that, in Brazilian 1- to 5 -year-old children, caries prevalence decreased significantly from 1996 to 2006, simultaneously with a reduction in the rate of caries progression.

Descriptors: Dental Caries; Diagnosis; Epidemiology.

\section{Introduction}

Over the last decade, there has been growing interest in diagnosing non-cavitated lesions in epidemiological studies involving large numbers of preschool and school-age children. ${ }^{1-7}$ In this context, the assessment of lesion characteristics indicating whether or not there is ongoing mineral loss is also considered relevant. The reasoning sustained by these studies is that diagnosis of the caries process limited to the cavitated level is no longer in accordance with current state-of-the-art knowledge in cariology. In particular, it contrasts with the current understanding of the development and arrest of the caries process at subclinical and clinical levels.

One may argue that the threshold for caries diagnosis should be tai- 
lored to the aim of the epidemiological study, since arguments can be made both ways. ${ }^{8}$ This is indeed a relevant aspect to consider because objectives may in some cases be achieved with the estimate measured only at a more severe stage of caries development. The need for operative treatment at the population or individual levels may well be measured by the diagnosis of the caries process into dentin or even into dental pulp. While this information is in itself important, when evaluated alone, it perpetuates the outdated concept that the caries process should be treated by restorations and extractions only. Thus, the contemporary needs for planning, delivery and monitoring of oral health care services at the population level are not fulfilled. ${ }^{9}$ This is true for populations of children, adolescents, young adults and, to some extent, adults up to 45 years of age. , $^{2,3,10,11}$

Currently, the major challenge in the management of the caries process is to control caries progression, mainly by delivering non-operative treatments and by limiting the number of individuals in a population subject to operative treatment. ${ }^{12}$ In this context, it is important to bear in mind that not all non-cavitated lesions progress to dentinal lesions requiring operative treatment, ${ }^{8}$ but many of them certainly require non-operative treatment to control further caries progression.

This paper highlights one topic of the lecture entitled "Caries Process: Evolving Evidence and Understanding" presented at the $18^{\text {th }}$ Congress of the Brazilian Association for Oral Health Promotion (Associação Brasileira de Odontologia de Promoção de Saúde - ABOPREV) in April 2013. In the framework of epidemiological studies, the interest in diagnosing active and inactive non-cavitated lesions was elucidated. However, relevant questions associated with the diagnosis of non-cavitated lesions that might raise concerns among researchers and health administrators were not addressed. The present paper aims to bring these questions into the discussion. The contribution of this discussion in terms of developing the available understanding of caries decline is analyzed by using data from a caries trends study in Brazilian preschool children residing in the Federal District of Brazil ${ }^{13}$ as an example.

\section{Are the field conditions suitable for the diagnosis of non-cavitated lesions?}

A major challenge in carrying out epidemiological studies is to develop the conditions required to perform a thorough clinical examination for caries and other oral health conditions as these studies are carried out at nurseries, schools, nursing homes and in-home settings. This includes training and calibration of the examiners and positioning of the participant for clinical examination, in addition to obtaining good lighting, and clean and dry teeth. The field equipment should include at least material and instruments such as toothbrushes, dental floss, portable lights, mouth mirrors, periodontal probes, dental probes and gauze bandages. Additional material and equipment may be required according to the subject of study and the resources available to the researcher, institution or government responsible for carrying out the epidemiological survey.

Thorough clinical examination may be performed under field conditions, including the diagnosis of non-cavitated lesions, by having calibrated dentists assess caries activity and severity at the non-cavitated level, by having participants lie down on tables and having their teeth professionally brushed, flossed and dried with gauze bandage and by working with portable lights. Good lighting may be obtained by means of frontal lamps. It is recommended that the professional perform the brushing and flossing while the participant lies down and subsequently dry the teeth with a gauze bandage. ${ }^{13}$ Thus, field conditions may become suitable for the diagnosis of non-cavitated lesions.

\section{Is the diagnosis of non-cavitated lesions reliable under field conditions?}

Several epidemiological studies recording noncavitated lesions have shown good reliability of the clinical assessments. ${ }^{3-7,10-12}$ Moreover, lesion activity assessment indicating whether or not there is ongoing mineral loss ${ }^{14,15}$ provides information of major importance for treatment decisions and implementation of strategies to control caries progression.

In our study, ${ }^{13}$ two calibrated examiners examined 225 preschool children to verify intra- and inter-examiner reliability in the diagnosis of caries. 
Under field conditions, the overall intra-examiner agreement showed non-weighted kappa values of 0.88 (95\% CI 0.86-0.90) for examiner 1 and 0.83 (95\% CI 0.80-0.86) for examiner 2. The inter-examiner value of 0.82 (95\% CI $0.81-0.83$ ) demonstrated almost perfect agreement. ${ }^{16}$

We went one step further in our analysis in order to independently verify the inter-examiner reliability in the diagnosis of active and inactive non-cavitated lesions. We also showed the non-weighted Kappa values obtained for active and inactive cavitated lesions since these values might be of interest.

The inter-examiner reliability in the diagnosis of active non-cavitated lesions was 0.75 (95\% CI 0.71-0.79), whereas for cavitated lesions the corresponding value was 0.81 (95\% CI 0.79-0.84). These findings indicated substantial agreement for both non-cavitated and cavitated active lesions. Examiner 1 had participated in data collection in previous epidemiological surveys and scored higher numbers of active non-cavitated lesions than Examiner 2 who was dealing for the first time with an epidemiological survey. However, the difference between them was not significant $(\mathrm{p}>0.06)$.

Additionally, the inter-examiner reliability in the diagnosis of inactive lesions was also measured at the non-cavitated and cavitated levels. The inter-examiner reliability for inactive non-cavitated lesions was 0.47 (95\% CI 0.40-0.55), whereas that for cavitated lesions was 0.88 (95\% CI 0.81-0.94). These results showed that the reliability of the diagnosis scores for inactive non-cavitated lesions was moderate, in contrast to that of cavitated lesions, which was 0.88 (95\% CI 0.82-0.94), almost substantial agreement. ${ }^{16}$

A more detailed analysis of our data looking at the intra-examiner reliability showed that Examiner 1 had a kappa value of 0.64 (95\% CI $0.44-0.85)$ and the corresponding value for Examiner 2 was 0.57 (95\% CI 0.32-082). Whereas Examiner 1 presented substantial agreement, Examiner 2 had moderate agreement that was probably reflected in the inter-examiner reliability. These results showed that the diagnosis of active non-cavitated lesions in the field work was reliable. However, the diagnosis of inactive non-cavitated lesions should be improved.

\section{Is the extra time required to record non- cavitated lesions in the field work a barrier?}

Time is an important issue when it comes to epidemiological surveys at a national level or any other survey including a high number of participants. There is no doubt that more time is required to carry out a clinical examination that includes the recording of non-cavitated lesions than one limited to cavitated lesions. Depending on the system chosen, the time required to record non-cavitated lesions may be double that of the system recommended by the World Health Organisation. ${ }^{17}$

Practitioners who are dealing with the recording of non-cavitated lesions for the first time spend more time than those who became familiar with it during their university training. In today's scenario, these aspects may be seen in the light of the increasing number of general practitioners whose university training in diagnosis of the caries process has been updated. In Brazil, this training seems to be spread across the country. In the near future, the recording of non-cavitated lesions will become very natural as a continuation of university training and this issue will lose its importance in due time. The extra time required to record non-cavitated lesions should not be considered a barrier, but should be taken into account when planning the field work.

\section{What is the impact of non-cavitated lesions on caries prevalence and severity?}

Our data showed significant differences in caries prevalence and severity when non-cavitated lesions were considered in the individual's caries experience. ${ }^{13}$ In this context, it is worth mentioning that in our studies very few children presented inactive non-cavitated lesions only. These cases were included in the group of participants classified as caries-free. Figures 1 and 2 illustrate the percentage distribution of caries-free Brazilian 1- to 5-year-old children in Cohort 1996 ( $\mathrm{n}=1,465)$ and in Cohort 2006 ( $\mathrm{n}=2,511$ ) according to two levels of examination. The children were classified as caries-free at two levels of examination. Free from any form of treated or untreated active as well as inactive caries lesions, i.e. $\mathrm{d}_{1} \mathrm{efs}=0$; and free from cavitated 
Figure 1 - Percentage distribution of caries-free Brazilian 1- to 5-year-old children in Cohort 1996 ( $n=1,465$ ) with their $d_{1}$ efs scores equal to " 0 " and their $\mathrm{d}_{3}$ efs scores equal to " 0 ". The number of children in each age group is denoted by " $\mathrm{N}$ ".

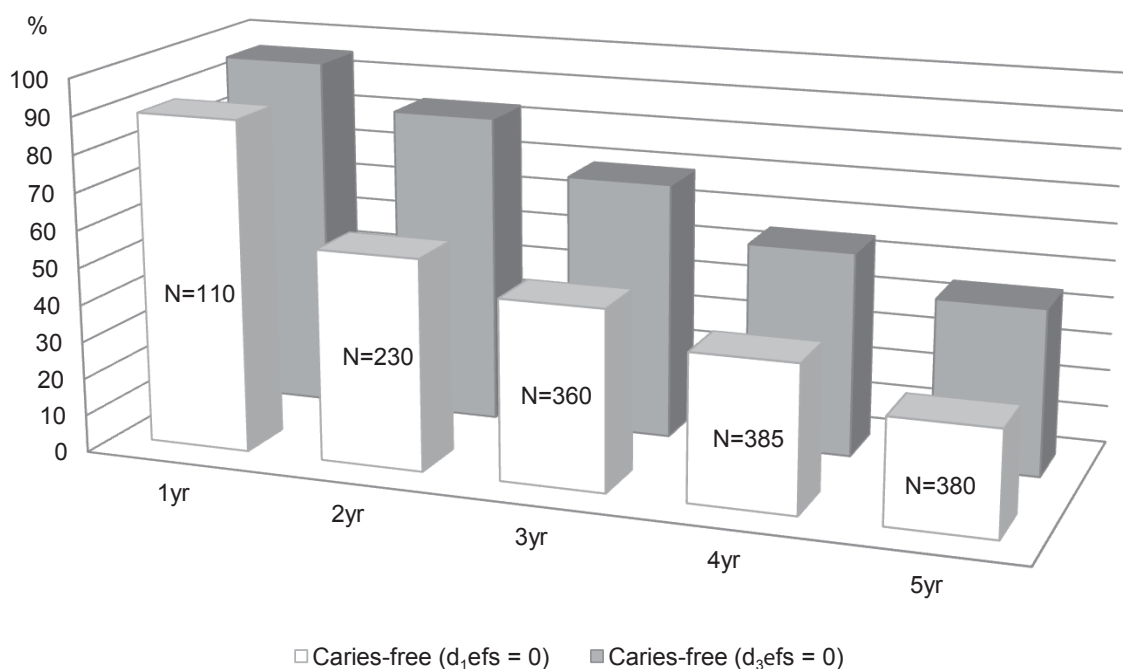

Figure 2 - Percentage distribution of caries-free Brazilian 1 - to 5 -year-old children in Cohort 2006 ( $n=2,511$ ) with their $d_{1}$ efs scores equal to " 0 " and their $\mathrm{d}_{3}$ efs scores equal to " 0 ".

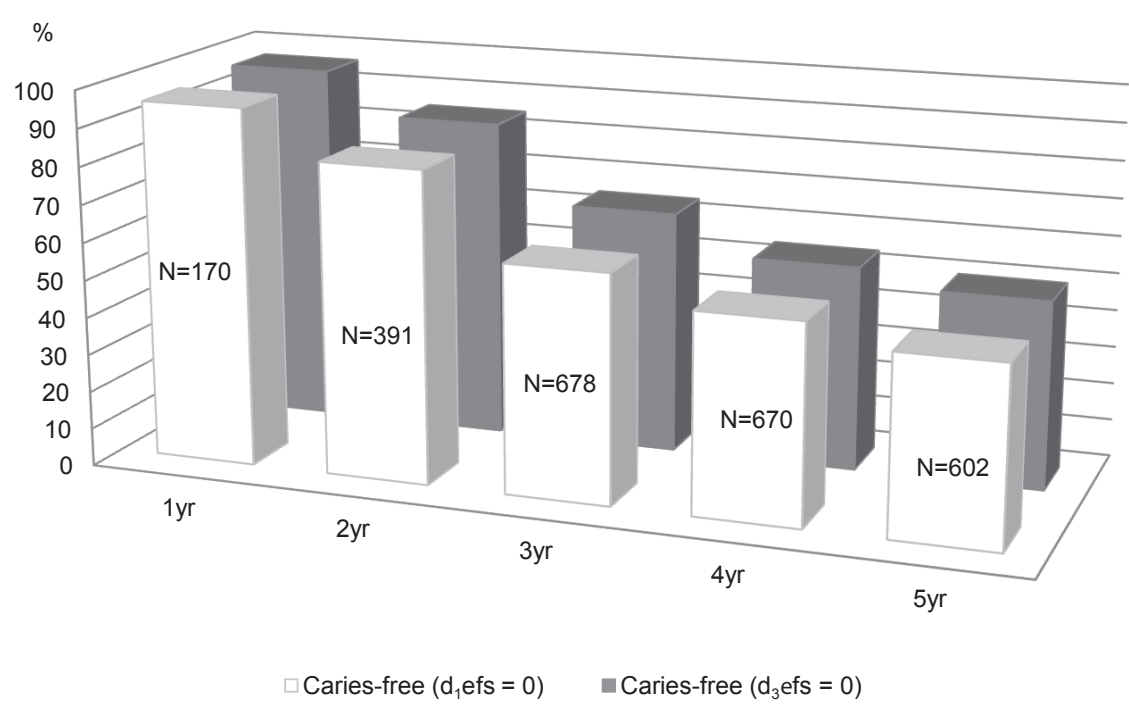

lesions, fillings and extracted teeth, i.e. $d_{3}$ efs $=0$ $\left(\mathrm{d}_{1}=\right.$ decayed at non-cavitated level for both active and inactive lesions, $\mathrm{d}_{3}=$ decayed at cavitated level for both active and inactive lesions, e = extracted, $\mathrm{f}=$ filled, $\mathrm{t}=$ tooth, $\mathrm{s}=$ surface). When comparing the percentages of caries-free children according to age and level of examination, significant differences, from the age of 2 years, were observed in Cohort 1996 ( $\mathrm{p}<0.001$ ). In Cohort 2006, differences were still present, but they were significant at the first level of examination only $(\mathrm{p}<0.05)$. Concerning caries severity, significant differences were observed between the mean number of $\mathrm{d}_{1} \mathrm{eft} / \mathrm{s}$ and $\mathrm{d}_{3} \mathrm{eft} / \mathrm{s}$ scores in Cohort 1996 ( $\mathrm{p}<0.001)$, while in Cohort 2006 this difference was important, but no longer significant $\left(\mathrm{p}=0.10\right.$; for details see Carvalho et al. $\left.{ }^{13}\right)$. The inclusion of active and inactive non-cavitated lesions gives a more realistic estimate of caries prevalence; at the same time, it gives further information about possible changes in caries activity and severity.

\section{What is the impact of non-cavitated lesions on caries decline?}

In our study, caries prevalence in preschool children decreased almost by half from 1996 to 2006 . The number of children free of any form of treated and untreated caries increased significantly in all age groups, as shown in Figures 1 and $2(\mathrm{p}<0.05)$. 
A marked reduction in terms of severity was registered for $d_{1} e f t / s$ scores from the age of 2 years $(\mathrm{p}<0.0005)$. However, a significant reduction at the $\mathrm{d}_{3} \mathrm{eft} / \mathrm{s}$ level was recorded at the tooth level only and limited to the 5 -year-old age group $(\mathrm{p}<0.0005)$. The reduction in the rate of caries progression during early childhood manifested itself as a significant reduction in the number of cavitated lesions at 5 years of age. The recording of non-cavitated lesions had a major impact on the results of the caries trends study, ${ }^{13}$ as it clearly showed that caries decline was still significant in the population studied. The observed caries decline was related to both active and inactive non-cavitated lesions.

\section{Discussion}

The traditional view that the diagnosis of the caries process is equivalent to that of cavitated lesions and that its treatment should be based on fillings and extractions is questioned in the present paper.

The main findings of the present paper were that the diagnosis of non-cavitated lesions was suitable and reliable when performed under field conditions and that the diagnosis of active and inactive noncavitated lesions significantly influenced caries outcomes.

There is general agreement that obtaining good conditions to perform a thorough clinical examination in the context of an epidemiological study is a major challenge. The present study described a methodology that circumvents this challenge, since it allows data collection with sufficient flexibility to be used in a variety of field settings and situations. It is therefore recommended for field work in countries with limited economic resources. This methodology was first implemented in the mid $1990 \mathrm{~s}^{1}$ and since then it has been used by our group for large epidemiological surveys. ${ }^{2,3,13}$ Concerning the reliability of the diagnosis of non-cavitated lesions in field work, most of the values obtained were compatible, either with almost perfect agreement or with substantial agreement. ${ }^{16}$ However, more efforts should be made to improve the diagnosis of inactive non-cavitated lesions, since it showed moderate agreement. In addition, experienced examiners seemed to score bet- ter than those who were dealing for the first time with an epidemiological survey.

Any system that records non-cavitated lesions requires more time for the clinical examination than the system recommended by the World Health Organization. This statement is in accordance with the literature, since the time required to record non-cavitated lesions may be doubled depending on the system chosen. ${ }^{17}$ However, it should be appreciated that practitioners who are dealing with the recording of non-cavitated lesions for the first time will spend more time than those who are familiar with it. The information obtained by recording active and inactive non-cavitated lesions should, in one way or another, compensate for the extra time employed during field work.

It is important to bear in mind that, traditionally, the caries process has been diagnosed at cavitated level for both prevalence and time-trend studies. ${ }^{18-26}$ Since the 1980 s, a leveling out of the decline of caries in the primary dentition has been reported in the literature. ${ }^{18,20,23,24}$ In some countries, however, recent studies still documented a decline in mean defs scores. ${ }^{2,3,19,21}$ In agreement with our results, studies in the literature showed significant differences in caries prevalence and severity in children, adolescents and young adults when non-cavitated lesions were considered in the individual's caries experience. ${ }^{1-4,7,10,11,17}$ The recording of active and inactive non-cavitated lesions had a major impact on the results of our caries trends study, as it clearly demonstrated that caries decline was still significant in the population studied. ${ }^{13}$

Finally, one may speculate about the reasons for the observed decline during the study period. The authors have no clear explanation, but they consider the following to be important. The children who participated in both cohort studies were from the same geographical area of the Federal District of Brazil, and were from low socio-economic backgrounds based on the family's monthly income and mother's educational level.

The children had daily access to fluoride as shown by the percentages of water samples, which fell within the standard range of $72 \%-84 \%$ (Cohort 1996) and of $78 \%-96 \%$ (Cohort 2006). ${ }^{13}$ In addi- 
tion, daily access to fluoride toothpaste was provided by the nursery schools for children from 3 years of age in Cohort 1996 and from 1 year of age in Cohort 2006. Fluoride reduces the rate of caries progression and this may partially explain our results. Other factors may have contributed to the caries decline, but they were not investigated in our study.

\section{Conclusion}

The interest in carrying out clinical examinations for caries diagnosis in epidemiological studies, which include diagnosis of active and inactive non-cavitated lesions, is highlighted in the present paper. By doing so, it was possible to demonstrate that caries prevalence and caries activity decreased significantly from 1996 to 2006 among Brazilian 1to 5 -year-old children, simultaneously with a reduc-

\section{References}

1. Carvalho JC, Mestrinho HD, Bezerra AC, Maltz M. Onset, development and arrest of dental caries in Brazilian pre-school children. Clin Oral Investig. 1998 Jun;2(2):96-100.

2. Carvalho JC, Van Nieuwenhuysen JP, D'Hoore W. The decline in dental caries among Belgian children between 1983 and 1998. Community Dent Oral Epidemiol. 2001 Feb;29(1):5561.

3. Carvalho JC, D'Hoore W, Van Nieuwenhuysen JP. Caries decline in the primary dentition of Belgian children over 15 years. Community Dent Oral Epidemiol. 2004 Aug;32(4):27782.

4. Machiulskiene V, Nyvad B, Baelum V. Prevalence and severity of dental caries in 12-year-old children in Kaunas, Lithuania 1995. Caries Res. 1998 May-Jun;32(3):175-180.

5. Silva BB, Maltz M. Prevalence of dental caries, gingivitis and fluorosis in 12-year-old students from Porto Alegre-RS, Brazil, 1998/1999. Pesqui Odontol Bras. 2001 Jul-Sep;15(3):208-214. Portuguese.

6. Alm A, Wendt LK, Koch G, Birkhed D. Prevalence of approximal caries in posterior teeth in 15 -year-old Swedish teenagers in relation to their caries experience at 3 years of age. Caries Res. 2007 Aug;41(5):392-8.

7. Ismail AI, Lim S, Sohn W, Willem JM. Predictors of dental caries progression in primary teeth. J Dent Res. 2009 Mar;88(3):270-5.

8. Fejerskov O, Kidd E. Dental Caries. The Disease and its Clinical Management. 2nd ed. Oxford: Blackwell Munksgaard; 2008. $126 \mathrm{p}$.

9. Pitts NB. Modern concepts of caries measurement. J Dent Res. 2004 Jul;83 Spec No C:C43-7. Review. tion in the rate of caries progression.

The reduction in the rate of caries progression manifested itself first by a significant increase in the percentage of children who were free from any form of clinically treated or untreated caries, including active and inactive non-cavitated lesions, and, second, by a significant reduction in the mean $d_{1} e f t / s$ scores in which non-cavitated lesions were included.

\section{Acknowledgment}

The author thanks the ABOPREV for the opportunity to lecture at the "Equity, Social Inclusion and Oral Health Promotion: Major Challenges" International Symposium, held at the $18^{\text {th }}$ Congress of the Brazilian Association for Oral Health Promotion (Associação Brasileira de Odontologia de Promoção de Saúde - ABOPREV).

10. Fontana M, Jackson R, Eckert G, Zandona AF, Ando M, Stookey GK, et al. Identification of caries risk factors in toddlers. J Dent Res. 2011 Feb;90(2):209-14.

11. Ismail AI, Sohn W, Tellez M, Willem JM, Betz J, Lepkowski J. Risk indicators for dental caries using the International Caries Detection and Assessment System (ICDAS). Community Dent Oral Epidemiol. 2008 Feb;36(1):55-68.

12. Carvalho JC, Thylstrup A, Ekstrand KR. Results after 3 years of non-operative occlusal caries treatment of erupting permanent first molars. Community Dent Oral Epidemiol. 1992 Aug;20(4):187-92 .

13. Carvalho JC, Figueiredo MJ, Vieira EO, Mestrinho HD. Caries trends in Brazilian non privileged preschool children in 1996 and 2006. Caries Res. 2009 Mar;43(1):2-9.

14. Thylstrup A, Bruun C, Holmen L. In vivo caries modelsmechanisms for caries initiation and arrestment. Adv Dent Res. 1994 Jul;8(2):144-57. Review.

15. Nyvad B. Diagnosis versus detection of caries. Caries Res. 2004 May-Jun;38(3):192-8. Review.

16. Landis JR, Koch GG. The measurement of observer agreement for categorical data. Biometrics. 1977 Mar;33(1):159-74.

17. Braga MM, Oliveira LB, Bonini GA, Bönecker M, Mendes FM. Feasibility of the International Caries Detection and Assessment System (ICDAS-II) in epidemiological surveys and comparability with standard World Health Organization criteria. Caries Res. 2009 Jul;43(4):245-249.

18. Marthaler TM. Changes in dental caries 1953-2003. Caries Res. 2004 May-Jun;38(3):173-81. Review.

19. Ferro R, Besostri A, Olivieri A, Stellini E, Mazzoleni S. Preschooler's dental caries experience and its trend over 20 years 
in a North-East Italian Health district. Eur J Paediatr Dent. 2007 Dec;8(4):199-204.

20. Truin GJ, van Rijkom HM, Mulder J, van't Hof MA. Caries trends 1966-2002 among 6- and 12-year-old children and erosive wear prevalence among 12-year-old children in The Hague. Caries Res. 2005 Jan-Feb;39(1):2-8.

21. Martins RJ, Garben CA, Garbin AJ, Moimaz SA, Saliba O. Declining caries rate in a municipality in northwestern São Paulo State, Brazil, 1998-2004. Cad Saude Publica. 2006 May;22(5):1035-41. Portuguese.

22. Ferreira SH, Béria JU, Kramer PF, Feldens EG, Feldens CA. Dental caries in 0 - to 5 -year-old Brazilian children: prevalence, severity, and associated factors. Int J Paed Dent. 2007 Jul;17(4):289-96.

23. Pitts NB, Boyles J, Nugent ZJ, Thomas N, Pine CM. The dental caries experience of 5 -year-old children in Great Britain
(2005/6). Surveys co-ordinated by the British Association for the study of community dentistry. Community Dent Health. 2007 Mar;24(1):59-63.

24. Bönecker M, Ardenghi TM, Oliveira LB, Sheiham A, Marcenes W. Trends in dental caries in 1- to 4-year-old children in a Brazilian city between 1997 and 2008. Int J Paediatr Dent. 2010 Mar;20(2):125-31.

25. Davies GM, Jones CM, Monaghan N, Morgan MZ, Neville JS, Pitts NB. The caries experience of 11 to 12 year-old children in Scotland and Wales and 12 year-olds in England in 2008-2009: reports of co-ordinated surveys using BASCD methodology. Community Dent Health. 2012 Mar;29(1):8-13.

26. World Health Organization. Oral Health survey - Basic methods. 4th ed. Geneva: World Health Organization (WHO); 1997. $66 \mathrm{p}$. 